\title{
Calcium Acetate
}

National Cancer Institute

\section{Source}

National Cancer Institute. Calcium Acetate. NCI Thesaurus. Code C47429.

A calcium salt of acetic acid. Calcium is a mineral essential for many cellular functions including nerve impulse transmission, muscle contraction, cardiac function, bone formation, and capillary and cell membrane permeability. Calcium acetate is administered orally to prevent or treat calcium deficiency and to treat hyperphosphatemia due to its phosphate-binding properties. 